\title{
Социология
}

DOI: $10.17805 /$ trudy.2017.5.1

\section{БЕЗОПАСНОСТЬ ЖИЗНЕДЕЯТЕЛЬНОСТИ В МЕГАПОЛИСЕ МОСКВА}

\author{
С. П. Бурцев \\ Московский гуманитарный университет
}

\begin{abstract}
Аннотация: В статье рассматриваются проблемы, нарушающие нормальную жизнедеятельность жителей города Москва, обсуждаются возможные механизмы градоразрушения, ухудшения физического и психического здоровья москвичей. Анализируется информированность граждан по различным аспектам безопасности в мегаполисе $u$ возможность использования социальных технологий предупреждения чрезвычайных ситуаций и их устранения.

Ключевые слова: безопасность жизнедеятельности; здоровье; здоровый образ жизни; социальное благополучие; чрезвычайная ситуация; социальные технологии; экологическая культура; мегаполис; Москва
\end{abstract}

\section{HEALTH AND SAFETY IN THE METROPOLIS OF MOSCOW}

\author{
S. P. Burtsev \\ Moscow University for the Humanities
}

\begin{abstract}
The article discusses the problems that affect the normal life of residents of the city of Moscow, discusses possible mechanisms of city disintegration, deterioration of Muscovites' physical and mental health. It analyses public awareness of various aspects of security in the city and the possibility of using social technologies to prevent emergencies and eliminate them.

Keywords: health and safety; health; healthy lifestyle; social welfare; emergency; social technologies; ecological culture; metropolis; Moscow
\end{abstract}

Город Москва - один из самых крупных на планете городов. По многим показателям он относится к мегаполисам. В 2017 г. численность населения Москвы составляла 12380664 человека при плотности 4834,31 чел/ кв.км. Вместе с Московской областью Москва образует единый социогеографический конгломерат. На 2017 г. Московской области проживало 
7423470 человек. Плотность населения составляла 167,46 чел/кв. км, а городское население области $81,67 \%$.

Москва, как мегаполис, имеет особенности, позволяющие отличать его от других крупных городов. В-первых, численность населения возрастает за счет интенсивной неконтролируемой миграции из всех регионов Российской Федерации, стран ближнего и дальнего зарубежья. При этом коренное население города фактически выдавливается потоком переселенцев в периферийные районы Москвы или за ее пределы. В итоге современное население Москвы, в большинстве своем не имеющее исторических городских корней, мало интересуется проблемами архитектурного облика, экологией и социальной инфраструктурой. Основная цель этой категории жителей получение финансового дохода, т. е. город Москва рассматривается ими не как «дом», а как «производственная среда». Вовторых, чрезмерно интенсивный рост населения требует постоянного расширения границ, вплоть, до объединения города с очень крупной территорией области (т. н. «Новая Москва»). Этот процесс привел к практически полному разрушению «зеленого пояса», что принципиально противоречит сущности понятия «мегаполис». В-третьих, Москва имеет очень специфическое историческое развитие. За время существования ее облик многократно радикально изменялся. Особенно быстро менялся архитектурный облик Москвы с начала 30-х годов по настоящее время.

В результате этих изменений была уничтожена историческая застройка центра и возведены типовые здания на окраине Москвы, не отличающие ее от других городов России. Надо отметить, что перспективные планы позитивного развития не были реализованы. В частности, деурбанистический подход, предлагаемый архитектором и социологом Михаилом Охитовичем (1896-1937 гг.), позволил бы избежать многих современных городских проблем. К большому сожалению, его ранняя гибель вследствие произвола работников НКВД не позволила в полной мере реализовать предложенный им план застройки Москвы, который был лишь частично выполнен при строительстве в Измайлово и Люблино в 40-е годы прошлого века. Оба эти района были уничтожены в 60-х годах и на их месте появились стандартные типовые многоэтажные дома, которые можно увидеть в любом другом городе России.

Целью данной работы является анализ экологической обстановки в Москве и представление полученных автором в результате эмпирического исследования (март 2017 г.) мнений коренных москвичей о наиболее сложных экологических и социальных проблемах города, возможностей их решения. 


\section{Нарушение безопасности жизнедеятельности факторами техносферы}

Техносфера (производственная среда) - это часть окружающей жителей Москвы среды, которая создана самим человеком. К ней относятся жилые здания, производственные постройки, технические средства и сооружения, транспорт, дороги и др. В техносфере осуществляется предметно-практическая деятельность человека, которая может приводить к гибели граждан, уничтожению окружающей природной среды, деградации и уничтожению ресурсов. В конце XIX в. техногенные воздействия повреждали 1\% мощности биосферы, а в начале XXI в. - от 12 до 15\% (Протасов, 2001).

Наибольшая угроза безопасности жизнедеятельности москвичей исходит от воздуха, загрязненного выхлопными газами автомобилей, полициклическими канцерогенами, синтезирующимися при контакте резины с асфальтом, а также продуктами неполного сгорания некачественного бензина. Эти воздействия очень часто вызывают онкологические заболевания системы внешнего дыхания (рак бронхов и легких), инфекционные (бронхит, пневмония) и инфекционно-аллергические (бронхиальная астма) болезни.

Помимо этого, авто и мототранспорт являются потенциальными источниками опасности для пешеходов и пассажиров, вследствие того, что в Москве очень низкая культура и мастерство управления транспортными средствами, практикуется езда в состоянии наркотического или алкогольного опъянения, распространена «мода» на превышение скорости и езду с нарушениями правил дорожного движения.

Немало потенциальных опасностей для жителей Москвы имеется в архитектурном комплексе. Это, прежде всего, относится к качеству строительства, которое ведется неквалифицированными рабочими из стран постсоветского пространства. В сочетании с непрофессиональным планированием жилых зданий (оно не учитывает почвенные особенности городских земель, в частности, большого количества болот), создается опасность проседания и обрушения высотных зданий. Точечная застройка и возведение домов высокой этажности резко увеличивает вероятность гибели большого количества жителей в случае пожара. Причинами этого являются невозможность оптимального размещения пожарной техники, отсутствие доступа к гидрантам, отсутствие специальной техники для тушения пожара на высоких этажах и низкая эффективность использования вертолетов из-за большой площади города и отдаленности базирования вертолетного отряда. Точечная застройка опасна также тем, что она затрудняет отвод канализационных вод, загрязняет московские реки, является источником неприятных запахов, формирует психологические 
и психические расстройства у жителей. Подобная застройка в центре города уродует его сложившийся архитектурный облик. Особую опасность представляет собой строительство сооружений общественного питания в парках около водоемов и расположение пунктов питания на первых этажах жилых домов. При этом сброс отходов осуществляется непосредственно в воду, а у жителей выше расположенных этажей, имеющих заболевания пищеварительного тракта, наблюдается обострение болезней, вследствие наличия постоянных запахов готовящейся пищи.

Для Москвы, пережившей за свою историю несколько глобальных этапов промышленного развития, характерна высокая степень загрязнения почвы продуктами опасных техногенных процессов. Наибольшая опасность исходит от радиоактивных отходов, находящихся либо в «могильника» (территория НИЦ «Курчатовский институт»), либо в «свободном» виде на полях аэрации. Так, при застройке района Марьино, который располагается на месте Люблинских полей аэрации, удаляли поверхностных слой грунта, в котором был значительно превышен допустимый уровень радиоактивности. Дополнительные сложности решения этой проблемы связаны с тем, что до сих пор отсутствует достоверный источник информации о радиоактивном загрязнении Москвы. Только с помощью историко-научных методов удалось получить информацию о наличии могильника животных в Кузьминском парке. Опыты на животных (козы и коровы) с использованием радиоактивных изотопов проводились академиком Российской академии медицинских наук П. Д. Горизонтовым, работавшим в 1930-1940-е годы в Московской ветеринарной академии (Патологическая ..., 1958).

Повышенный радиационный фон длительное время регистрировался на берегу Москвы-реки и в ее водах в районе Москворецкого железнодорожного моста. Предположительно, источником выброса могли явиться лаборатории НИЯУ МИФИ. Химическое загрязнение в Москве чаще всего формировалось многочисленными свалками, которые располагались непрерывным широким поясом, соответствующим, проекции современного третьего транспортного кольца. Наиболее массовыми являлись Живодеровка (современная площадь Гагарина) и Южнопортовая. Теперь это места массовой жилой застройки.

Помимо этого, на территории Москвы имеются несколько бывших промышленных зон, где длительное время загрязнялась почва и вода: район Площади Ильича, Нижние Котлы, Капотня, Угрешская улица, Хорошевское шоссе. Имеются сведения загрязнения почв авиационным топливом в районах бывших московских аэродромов на Ходынском поле, в Текстильщиках, Теплом Стане, Измайлове. Последствия военнохимического загрязнения до сих пор можно видеть в Кузьминском парке 
в районе Чагинской улицы. Там, с 1918 по 1937 гг. располагался химический полигон Красной армии и исследовательская база НИИ химического машиностроения. До сих пор последствия химического загрязнения не устранены: отсутствует прудовая фауна, на земле лежат проржавевшие бочки с надписью «Иприт».

Серьезные проблемы, связанные с водоснабжением, водоотведением и состоянием водоемов, сформировались в Москве с начала 1970-х годов, когда началась массовая застройка города. На сегодняшний день в городе нет ни одного естественного водоема, где разрешено купание. Причинами такого положения дел являются загрязнение водохранилищ на севере Московской области сточными канализационными водами, т. к. на местах водоохранных территорий с начала 1990 -х годов располагаются частные землевладения. Это требует дополнительных усилий по очистке питьевой воды с помощью химических реагентов, в частности, хлора. В связи с этим водопроводная вода, не подвергшаяся кипячению, является токсичной.

Второй важной причиной служит загрязнение малых рек и прудов Москвы промышленными выбросами. Источниками являются предприятия питания, работающие в парках, где имеются водоемы, метрополитен, малые предприятия, производящие продукцию с жидкими и твердыми отходами, автосервисы и автомойки, а также офисные и жилые здания. Так широкий резонанс получило отравление воды в реке Котловка, после того как на ее берегу было возведено здание Газпрома. Наиболее загрязненной ядовитыми веществами является река Нищенка, протекающая с севера на юг по промышленным зонам Перово, Карачарово, Перерва. В последние годы среди обитателей водоемов отмечаются существенные наследственные аномалии развития. Так в Люблинском пруду появились рыбы без глаз, с удвоением плавников или неправильно развитой чешуей. Все это является результатом антропогенного отравления водоемов Москвы.

\section{Нарушение безопасности жизнедеятельности факторами природной и социальной среды}

Чрезвычайно важно, что интенсивная производственная антропогенная деятельность во многом компенсируется охранительным действием окружающей жителей Москвы природной средой. В лесах и парках Москвы обитают многочисленные животные: лоси, лисы, зайцы, многие вид птиц, земноводные и пресмыкающиеся. Правда, в последние годы, ареалы их распространения уменьшаются. Это стало побудительным фактором восстановления зеленого массива города: за последний год произведена посадка деревьев на центральных улицах, в парках и на бульварах.

На территории города наиболее опасным природным фактором являются болотистые участки. Как было сказано выше, сложные проблемы 
могут формироваться при строительстве высотных зданий на неустойчивой зыбкой почве.

Вторая существенная проблема - это возгорание торфяных болот. В каждое жаркое лето на Москву движется смог с востока области, что приводит обострению многих хронических заболеваний сердечно-сосудистой системы, легких, иммунной системы и др.

Роль биологических факторов, влияющих на здоровье населения Москвы чрезвычайно высока. Действие этих факторов тесно связано с социально-политическими условиями. Так, вследствие большой плотности населения, эпидемиологические заболевания протекают с широким размахом.

В последние годы в Москве существенно изменилась структура инфекционной заболеваемости. Главным образом, это объясняется плохо контролируемой миграцией, недостатком у граждан средств на покупку эффективных современных препаратов и их нежеланием проходить ежегодную диспансеризацию. В конце 1970-х годов в Москве усилиями фтизиатров и эпидемиологов практически был ликвидирован туберкулез, но к концу 1990-х годов его заболеваемость увеличилась почти в 60 раз. Такой рост связан, прежде всего, с притоком мигрантов из Восточной Африки, Юго-восточной Азии и среднеазиатских государств. Заболевания клещевым дальневосточным энцефалитом стали наблюдаться после создания многолюдной китайской диаспоры в Москве. Известно, что Дальневосточная научная экспедиция под управлением Л. А. Зильбера (формальным руководителем был академик Е. Н. Павловский) выяснила, что вирус энцефалита является селективным биологическим оружием, разработанным японскими микробиологами против китайских граждан в начале 1930-х годов. Вспышки орнитоза и бешенства в Московском регионе обусловлены употреблением в пищу диких голубей и бродячих собак вьетнамцами и корейцами. Существенное увеличение заболеваемости болезней, передающихся половым путем, связано с созданием огромного нелегального рынка интимных услуг, путем вовлечения в него представителей самых разных регионов Земли.

Таким образом, выявляется прямая взаимозависимость формирования природных и социальных неблагоприятных факторов.

Социальные факторы, ухудшающие здоровье и нарушающие трудовую деятельность жителей крупных городов, весьма многообразны.

Специфическим признаком функционирования мегаполиса является высокая скорость различных жизненных составляющих. Это является одной из основных причин внезапной смерти у молодых людей, частота которой в последние годы резко возросла.

Сложной, трудно решаемой проблемой является обеспечение 
социально-правовой безопасности большинства граждан Москвы. Статистические сведения и многочисленные данные социологических исследований свидетельствуют о наличии высокого уровня коррумпированности во властных структурах, Министерстве внутренних дел и судебных органах. Гражданские права многих жителей Москвы ограничены законодательством, разрешающим в отношении их внесудебные приговоры, нарушение принципа «презумпции невиновности», покушения на жизнь со стороны криминальных коллекторских структур. Большую угрозу для москвичей представляет организованная и бытовая преступность. 97\% всех преступлений в Москве совершается приезжими из периферийных городов России и мигрантами. Преступные конфессиональные группировки контролируют различные сферы жизнедеятельности города: азербайджанские - продажу сельхозпродукции, грузинские - занимаются квартирными кражами, чеченские и цыганские - продажей психоактивных веществ, африканцы - мошенничествами.

В Москве не проводится достаточной спортивно-оздоровительной работы с детьми и молодежью, мало доступных спортивных секций и кружков. Как видно из наших личных наблюдений, многие студенты Московского гуманитарного университета имеют деформации скелета, избыточный или недостаточный вес, хронические социально значимые заболевания (гипертоническая болезнь, сахарный диабет, инфекционные болезни) (Бурцев, 2016). Такое положение дел усугубляется крайне неудачной «оптимизацией» московского здравоохранения, которая привела к оттоку узких специалистов из первичного звена здравоохранения и фактической недостаточности специализированной медицинской помощи. Частная система московского здравоохранения и добровольное медицинское страхование недоступны большинству населения из-за высокой стоимости услуг.

Совершенно нетерпимой является ситуация с московскими пенсионерами. Их пенсия едва покрывает оплату услуг жилищно-коммунальных служб. Трудоустройство практически невозможно, а убийства одиноких стариков криминалом, действующим в сфере продажи квартир, происходят часто. Нередко пенсионеры, живущие за чертой бедности, вынуждены неофициально сдавать жилье представителям криминальных структур, что существенно затрудняет розыск преступников.

В 2017 г. исполнилось 40 лет с начала террористической деятельности против жителей Москвы. В январе и феврале 1977 г. произошли взрывы в метро и магазинах в центре города, а также пожар в гостинице «Зарядье». Они были организованы армянскими националистами совместно с криминальными структурами. Возобновилась активная террористическая деятельность с середины 1990-х годов и продолжается до сих пор. 
В такой ситуации является актуальным формирование новых и использование классических технологий охраны здоровья и окружающей среды, безопасного поведения и жизнедеятельности.

\section{Результаты собственного научного исследования}

Целью социологического исследования было изучение информированности коренного населения Москвы о безопасном поведении и его мнения о технологиях социальной работы в условиях различных видов опасностей в мегаполисе. Методом сбора социологической информации было выбрано анкетирование. Респондентами являлись студенты и сотрудники Московского гуманитарного университета, а также жители Восточного, Юго-Восточного и Южного административных округов города Москвы. Все 42 респондента являются москвичами в 3-м поколении. Исследование проводилось в марте 2017 г.

В исследовании принимали участие 79\% женщин и 21\% мужчин. Возрастной состав респондентов: 56\% - 20 и менее лет, $18 \%$ - от 21 года до 50 лет, 26\% - старше 50-ти лет.

Социальные негативные проблемы, по мнению жителей Москвы, располагаются в следующей последовательности: высокая стоимость жизни (79\%), большая плотность населения (65\%), уменьшение числа потомственных москвичей (50\%), низкое качество доступных продуктов и непомерно высокие налоги - по 44\%, нарушение санитарно-эпидемиологических норм (38\%), искажение сложившегося архитектурного города (32\%), сложная криминальная обстановка (15\%). Причем, мнение о высокой стоимости жизни, заняло безоговорочное первое место во всех возрастных группах: 84\% - у молодых, 67\% - среди лиц среднего возраста и $78 \%$ - у респондентов старшей группы. Для 20-летних значимыми проблемами являются высокие налоги и уменьшение числа потомственных москвичей, для граждан среднего возраста - большая плотность населения и низкое качество доступных продуктов, а для старшей группы уменьшение числа потомственных москвичей и нарушение санитарноэпидемиологического благополучия.

Экологические проблемы были распределены респондентами в следующем порядке: загрязнение воздуха выхлопными газами автомобилей (68\%), загрязнение почвы и воды антигололедными реагентами (65\%), застройка Подмосковья многоэтажными жилыми домами и уничтожение зеленого пояса Москвы (62\%), переработка мусора (53\%), уничтожение парков и скверов (44\%), негативные изменения климата (24\%). Для 20летних респондентов наиболее актуальной причиной является ухудшение свойств почвы химическими противогололедными средствами, для респондентов среднего возраста - загазованность воздуха, а для старше- 
го возраста - уменьшение площадей городских садов и парков.

Вести здоровый образ жизни жителям Москвы не позволяют низкое качество доступного питания (56\%), плохая экология (53\%) и недоступность современных качественных спортивных сооружений (38\%). 98\% респондентов считают, что ситуацию с социальными и экологическими угрозами, должны предупреждать сами граждане Москвы.

Выяснилось, что респонденты недостаточно информированы о различных видах экологических катастроф, которые могут развиваться в мегаполисах (25\% мужчин и 34\% женщин). Наиболее важные социальные последствия катастроф в мегаполисах распределились в следующей последовательности: утрата близких (30\% мужчин и 38\% женщин), потеря жилья (8\% мужчин и 40\% женщин), рост общей заболеваемости (12\% мужчин и $28 \%$ женщин), недоступность медицинской помощи (14\% мужчин и $30 \%$ женщин), утрата документов (2\% мужчин и 14\% женщин), рост преступности (2\% мужчин и $18 \%$ женщин).

Как видно из результатов, женщины Москвы проявляют или готовы проявить большую социальную ответственность в моменты развития различных кризисных ситуаций. Среди наиболее важных мероприятий по предупреждению чрезвычайных ситуаций в крупных городах мужчины называли «усиление контроля за деятельностью промышленных предприятий» (24\%), а женщины - «формирование экологической культуры» и «усиление ответственности за нарушение экологической безопасности» (по 34\%).

На вопрос «Что Вы понимаете под экологической культурой?» были получены такие варианты ответов:

1) бережное отношение к природе;

2) соблюдение норм безопасности в окружающей среде;

3) следование законам природы;

4) взаимосвязь человека с окружающей средой;

5) разумное поведение человека в окружающем мире, бережное отношение к окружающему миру;

6) соблюдение обществом и каждым человеком экологических законов;

7) полное понимание взаимосвязи между деятельностью человека и окружающей средой;

8) обязательное выполнение экологических законов;

9) форма поведения человека, при которой не наносится ущерб окружающей среде.

Наибольшая эффективность деятельности по предупреждению нарушений безопасности жизнедеятельности жителей мегаполисов, достигается путем проведения четкой динамичной государственной политики в 
этой области и разносторонней социальной работы с различными социальными группами населения и каждым отдельным гражданином. Роль государства, всех его уровней организации и ветвей власти заключается в неукоснительном требовании соблюдения законодательства в области охраны здоровья и безопасности граждан, а также сохранении нормальной экологической среды. Значение государственных структур в экологическом образовании и просвещении в настоящее время невелико, но они могут повысить свою результативность, если работа в этом направлении будет являться частью социальных программ в отдельных административных округах. Работа с населением может иметь такой вектор, как экологическое просвещение в рамках формального образования, воспитание в детских эколого-оздоровительных лагерях, создание экологических клубов для детей и подростков, курсы повышения квалификации учителей школ и преподавателей вузов, экологическое образование медицинских работников. Социальная работа в области охраны здоровья и безопасности жизнедеятельности в мегаполисах может включать в себя:

- мероприятия по предупреждению социально значимых заболеваний и репродуктивного здоровья;

- формирование установок на здоровый образ жизни;

- обеспечение социальной поддержки граждан в области охраны здоровья;

- организацию и проведение медико-социальной экспертизы;

- осуществление медицинской, психологической, профессиональной и социальной реабилитации, сопровождение в инклюзивном образовании (Технология ..., 2005).

\section{Заключение}

В заключении можно отметить, что город Москва как мегаполис относится к категории регионов с повышенным уровнем опасности для здоровья и социального благополучия. Специфическими признаками являются необычайно широкие различия социальных групп по многим признакам. Коренные жители Москвы, несмотря на большое количество разнообразных социальных проблем, обусловленных стремительным ростом города и неконтролируемой миграцией, активно участвуют в процессах формирования безопасности жизни, главным образом, в решении экологических проблем. 


\section{СПИСОК ЛИТЕРАТУРЫ}

Бурцев, С. П. (2016) Медико-социальный компонент инклюзивного образования в Московском гуманитарном университете // Ученый совет. № 3. C. 12-14.

Патологическая физиология острой лучевой болезни (1958) / под ред. П. Д. Горизонтова. М. : Медгиз. 375 с.

Протасов, В. Ф. (2001) Экология, здоровье и охрана окружающей среды в России : учебное и справочное пособие. М. : Финансы и статистика. 672 c.

Технология социальной работы в различных сферах жизнедеятельности : учебное пособие. (2005) / под ред. П. Д. Павленка. М. : Дашков и К. $236 \mathrm{c}$.

Дата поступления: 30.08.2017 г.

Бурщев Сергей Петрович - кандидат медицинских наук, профессор кафедры социологии Московского гуманитарного университета. Адрес: 111395, Россия, г. Москва, ул. Юности, д. 5. Тел.: + 7 (499) 374-60-21. Эл. адрес: sergei-burcew@mail.ru.

Burcew Sergei Petrovich, Candidate of Medicine, Professor, Department of Sociology, Moscow University for the Humanities. Postal address: 5, Yunosti St., Moscow, Russian Federation 111395. Tel.: +7 (499) 374-60-21. E-mail: sergei-burcew@mail.ru

\section{Для циитирования:}

Бурцев С. П. Безопасность жизнедеятельности в мегаполисе Москва [Электронный ресурс]// Научные труды Московского гуманитарного университета. 2017. № 5. URL: http://journals.mosgu.ru/trudy/article/view/563 DOI: 10.17805/trudy.2017.5.1 (дата обращения: дд.мм.гг.) 